\title{
Selecting appropriate variables for detecting grassland to cropland changes using high resolution satellite data
}

\author{
Tomáš Klouček ${ }^{\text {Corresp.. }}{ }^{1}$ ， David Moravec ${ }^{1}{ }^{\text {, Jan Komárek }}{ }^{1}{ }^{\text {, }}$, Ondřej Lagner ${ }^{1}{ }^{\text {, Přemysl Štych }}{ }^{2}$ \\ ${ }^{1}$ Department of Applied Geoinformatics and Spatial Planning, Faculty of Environmental Sciences, Czech University of Life Sciences Prague, Czech \\ University of Life Sciences Prague, Prague, Czech Republic \\ 2 Department of Applied Geoinformatics and Cartography, Faculty of Science, Charles University in Prague, Charles University in Prague, Prague, Czech \\ Republic \\ Corresponding Author: Tomáš Klouček \\ Email address: tkloucek@fzp.czu.cz
}

Grassland is one of the most represented, while at the same time, ecologically endangered land cover categories in the European Union. In view of the global climate change, detecting its change is growing in importance from both an environmental and a socioeconomic point of view. A well-recognised tool for Land Use and Land Cover (LULC) Change Detection (CD), including grassland changes, is Remote Sensing (RS). An important aspect affecting the accuracy of change detection is the finding the optimal indicators of LULC changes (i.e. variables). Inappropriately selected variables can produce inaccurate results burdened with a number of uncertainties. The aim of our study is to find the most suitable variables for the detection of grassland to cropland change, based on a pair of high resolution images acquired by the Landsat 8 satellite and from the vector database Land Parcel Identification System (LPIS). In total, 59 variables were used to create models using Generalised Linear Models (GLM), the quality of which was verified through multi-temporal object-based change detection. Satisfactory accuracy for the detection of grassland to cropland change was achieved using all of the statistically identified models. However, a three-variable model can be recommended for practical use, namely by combining the Normalised Difference Vegetation Index (NDVI), Wetness and Fifth components of Tasselled Cap. Increasing number of variables did not significantly improve the accuracy of detection, but rather complicated the interpretation of the results and was less accurate than detection based on the original Landsat 8 images. The results obtained using these three variables are applicable in landscape management, agriculture, subsidy policy, or in updating existing LULC databases. Further research implementing these variables in combination with spatial data obtained by other RS techniques is needed. 
1 Selecting appropriate variables for detecting grassland to cropland changes 2 using high resolution satellite data

3 Tomáš Klouček ${ }^{1}$, David Moravec ${ }^{1}$, Jan Komárek ${ }^{1}$, Ondřej Lagner ${ }^{1}$, Přemysl Štych ${ }^{2}$

$4 \quad{ }^{1}$ Department of Applied Geoinformatics and Spatial Planning, Faculty of Environmental Sciences, 5 Czech University of Life Sciences Prague, Kamýcká 129, Praha - Suchdol, 165 00,

6 Czech Republic

$7 \quad{ }^{2}$ Department of Applied Geoinformatics and Cartography, Faculty of Science, Charles University

8 in Prague, Albertov 6, 12843 Prague 2, Czech Republic

9

10 Corresponding Author:

11 Tomáš Klouček ${ }^{1}$

12 Kamýcká 129, Praha - Suchdol, 165 00, Czech Republic

13 Email address: tkloucek@fzp.czu.cz 


\section{Abstract}

Grassland is one of the most represented, while at the same time, ecologically endangered land cover categories in the European Union. In view of the global climate change, detecting its change is growing in importance from both an environmental and a socio-economic point of view. A wellrecognised tool for Land Use and Land Cover (LULC) Change Detection (CD), including grassland changes, is Remote Sensing (RS). An important aspect affecting the accuracy of change detection is the finding the optimal indicators of LULC changes (i.e. variables). Inappropriately selected variables can produce inaccurate results burdened with a number of uncertainties. The aim of our study is to find the most suitable variables for the detection of grassland to cropland change, based on a pair of high resolution images acquired by the Landsat 8 satellite and from the vector database Land Parcel Identification System (LPIS). In total, 59 variables were used to create models using Generalised Linear Models (GLM), the quality of which was verified through multitemporal object-based change detection. Satisfactory accuracy for the detection of grassland to cropland change was achieved using all of the statistically identified models. However, a threevariable model can be recommended for practical use, namely by combining the Normalised Difference Vegetation Index (NDVI), Wetness and Fifth components of Tasselled Cap. Increasing number of variables did not significantly improve the accuracy of detection, but rather complicated the interpretation of the results and was less accurate than detection based on the original Landsat 8 images. The results obtained using these three variables are applicable in landscape management, agriculture, subsidy policy, or in updating existing LULC databases. Further research implementing these variables in combination with spatial data obtained by other RS techniques is needed. 
37

38

39

40

41

42

\section{Introduction}

Land Use and Land Cover (LULC) techniques form an integral part of many studies (Kindu et al., 2013; Gupta \& Shukla, 2016; Chaudhuri \& Mishra, 2016) overlapping with other research fields (Cardinale et al., 2012). LULC is considered an important factor influencing the environment and its changes have a demonstrable impact on climate change (Tasser, Leitinger \& Tappeiner, 2017). Among the land cover types in the European Union (EU), grassland and cropland are the most prominent, accounting for $44 \%$ of the total area (Eurostat, 2017). Since the 1990 s, the main LULC change trends in most post-communist Central European countries are afforestation, grassing over, intensification, and urbanisation. Even though the change of grassland to cropland is not as frequent a transition as it was during the communist era (Kupková \& Bičík, 2016), it still elicits a significant impact on the ecosystem. Grassland plays an irreplaceable role as a natural habitat of many organisms, helps with the accumulation of greenhouse gases, prevents erosion, keeps water in the landscape and reduces pollution (European Union, 2016). However, these benefits are easily disrupted by ploughing the grassland, thus turning it into cropland. It is, therefore, important to detect such changes, quantify them and continuously monitor the developments. The occurrence of new cropland at the expense of grassland is especially prominent in post-communist states that have recently joined the EU and started to receive agricultural subsidies (Pazúr et al., 2014). This process is also affected by a number of national and European agricultural policies and initiatives (Sklenicka et al., 2014), such as the Good Agricultural and Environmental Conditions (GAEC) (Sklenicka et al., 2015). Change data acquired from remote sensing based models can, therefore, serve both as a basis for decision-making in the landscape management and have a socio-economic application in agriculture and its subsidy policy (Esch et al., 2014). 
60

spectral satellite images are one of the most commonly used types of RS data, among which Landsat satellites images stand out due to long-term imaging, a suitable compromise between spectral, spatial and temporal resolution and free availability (Wulder et al., 2008; Xian, Homer \& Fry, 2009; Chen et al., 2012; Roy, Ghosh \& Ghosh, 2014). LULC change detection using RS data is based on the theoretical assumption that each LULC type has its own typical spectral signatures. If an LULC type changes, so will change its spectral signatures (Hussain et al., 2013). In practice, it is often difficult to distinguish the signal of true changes from the false signals arising from external factors (different atmospheric conditions, soil moisture, or the phenological stage (Jensen, 1996)), the selection of RS data ( $\mathrm{Lu}, \mathrm{Li} \&$ Moran, 2014), pre-processing (Dai, 1998) and atmospheric corrections (Song et al., 2001), the choice of the change detection method, the selection of the variables or the inexperience of the analyst (Lu et al., 2003). The significance of these uncertainties is even greater in LULC objects with very similar spectral signatures, which is exactly the case of croplands with a high degree of heterogeneity and significant effects of different phenological phases of individual crops and plants (Lu et al., 2003).

Some studies dealing with the classification and change detection of grassland and cropland have been published (Chen \& Rao, 2008; Esch et al., 2014). These categories are often a part of a comprehensive change detection study (Mas, 1999; Bergen et al., 2005; Wondrade, Dick \& Tveite, 2014; Vorovencii, 2014). We can also find studies aimed at a more detailed classification on the level of individual croplands (Wardlow, Egbert \& Kastens, 2007; Turker \& Ozdarici, 2011) or on grassland change detection (Weeks et al., 2013). Studies focusing specifically on grassland to cropland change are, however, still exceedingly rare (Tarantino et al., 2016). Among the studies closest to the topic of our study, the papers by Tarantino et al. (2016), who achieved 86.91\% 
82 accuracy in the detection of semi-natural grassland to cropland changes in Italy using a cross-

83

84

85

86

87

88

89

90

91

92

93

94

95

96

97

98

correlation analysis of Landsat 8 OLI images, and by Weeks et al. (Weeks et al., 2013), who used

NDVI differencing for the change of "indigenous" grasslands in New Zealand and achieved 56\% accuracy, can be mentioned.

Many papers have been published that reviewed the methods and techniques used for the detection of LULC changes (Singh, 1989; Lyon et al., 1998; Lu et al., 2003; Coppin et al., 2004; Berberoglu \& Akin, 2009; Bhandari, Kumar \& Singh, 2012; Hussain et al., 2013; Lu, Li \& Moran, 2014; Tewkesbury et al., 2015), in forest ecosystems (Coppin \& Bauer, 1996; Woodcock et al., 2001; Lu, Batistella \& Moran, 2008), urban areas for building detection (Liu \& Zhou, 2004; Sohn \& Dowman, 2007; Aleksandrowicz et al., 2014) or for the detection of imperious surfaces (Xian, Homer \& Fry, 2009). Other studies focus on the problem of mapping the general land use change (Yin et al., 2014) or on agricultural land specifically (Weeks et al., 2013; Müller et al., 2015; Tarantino et al., 2016). The application of RS in agriculture is summarised, for example, in a review by Atzberger (2013). The current trend uses a time series for agricultural change detection (for example, all the available Landsat imagery), which provides additional phenological information (Müller et al., 2015). In many cases, an insufficient number of satellite images is available due to cloud cover and, therefore, bi-temporal change detection is still needed. The alternative approach uses imagery from two dates, for which the time of the acquisition and the variable selection are crucial. The potential usefulness of various $\mathrm{CD}$ variables and their impact on LULC CDs has not been sufficiently studied either.

Variables used for CD may be divided into three categories. One category consists of spectral variables that include spectral bands and derived vegetation indices, transformed images, segments, sub-pixel features, and classification results. The second category includes spatial 
105

106

107

108

109

110

111

112

113

114

115

116

117

118

119

120

121

122

123

124

125

126

127 128

variables such as textures, different scales, the complexity of the landscape or topography. The temporal variables comprise the third category (Lu, Li \& Moran, 2014). With more than 40 modifications, vegetation indices form the most numerous group of variables (Bannari et al., 1995). Significant variability and the amount of RS data, as well as the choice of variables, are very likely to affect the LULC CD, as was shown in other spatial analyses (Barry \& Elith, 2006; Moudrý \& Šímová, 2012; Klouček, Lagner \& Šímová, 2015). Using a large number of variables can potentially improve the accuracy of the $\mathrm{CD}$. On the other hand, such an approach can introduce a number of uncertainties into the detection and make the interpretation of obtained results difficult (Lu \& Weng, 2007).

Despite the fact that LULC change detection has been one of the most discussed RS topics for decades, to the best of our knowledge, only few studies have focused their attention on selection of appropriate variables for detection of changes in croplands. The aim of our study is to find the optimal variable(s) for grassland to cropland detection based on the Landsat 8 OLI high resolution data and the vector database, called the Land Parcel Identification System (LPIS), and to test the results for the 2013-2016 period on the selected territory. We hypothesised that (1) it is possible to find a suitable variable or group of variables capturing the change of the grassland to cropland due to different spectral profiles; (2) the greater the amount of the incorporated variables, the more accurate the CD would be; (3) spectral variables would be more significant than textural ones; (4) an important aspect of the grassland to cropland change detection would be the time of the acquisition input satellite data.

\section{Materials and Methods}

\subsection{Study area}

The study area is located in Central Europe, namely in the western part of the Czech Republic intersecting with Landsat 8 scene No. $192 / 25$ with centre point coordinates approximately $50^{\circ} 22^{\prime}$ 
$129 \mathrm{~N}, 13^{\circ} 41^{\prime} \mathrm{E}$, see Figure 1. The study area is on a regional scale (approx. 36,260 $\mathrm{km}^{2}$ ) and is

130 characterised by notable variability (topographical, landscape ecology as well as vegetational

131 variability). This scale and localisation therefore warrants the occurrence of a sufficient number of

132 both grassland to cropland changes and of no-change areas. The expected occurrence of changes

133 was manually verified prior to the analysis using freely available CORINE Land Cover data

134 (http://land.copernicus.eu/pan-european/corine-land-cover/).

135 (Figure 1)

136

\subsection{Input data}

137 The main data source was a pair of high resolution images taken by the Landsat 8 OLI on August $1383^{\text {rd }}, 2013$ and August 27 th 2016 . The images downloaded from the US Geological Survey 139 (http://earthexplorer.usgs.gov/) contain 9 spectral bands with a resolution of $30 \mathrm{~m}$ (multi-spectral) 140 and $15 \mathrm{~m}$ (panchromatic), respectively. Detailed specifications of the OLI sensor can be found in 141 Roy et al. (2014). At the time of the image selection, the chosen images were the only one's 142 available for a pair of scenes that, besides being almost cloudless, also met the other criteria 143 including the suitable extent, the sufficient temporal distance between the imaging data, and 144 acquisition at the suitable phenological stage. The most suitable period for the grassland to 145 cropland change detection is the period shortly after harvest (late summer, early autumn) (Esch et 146 al., 2014).

147 As a source of reference data on the use of the agricultural land, we used the Land Parcel 148 Identification System and its vector database containing the land use data for the entire territory of 149 the Czech Republic from 2004. The basic unit of LPIS is a group of adjacent plots representing a 150 continuous area farmed by a single farmer with a single crop plant. The database classifies the 151 agricultural land into 11 land use categories. Data from years corresponding with the Landsat 
152 images, i.e., 2013 and 2016, was used, see Figure 2. In accordance with LPIS classification, 153 cropland is defined as a "farmed land producing crop plants requiring annual replanting, which is 154 not grassland" in this study. Grassland, on the other hand, is defined as a "farmed land under 155 permanent pasture or, where appropriate, contiguous vegetation dominated by grass, used 156 predominantly for feeding or technical purposes" (The Ministry of Agriculture of the Czech 157 Republic, 2016).

158 (Figure 2)

159

160

161

162

163

164

165

166

167

168

169

170

171

172

173

174

\subsection{Images and data pre-processing}

Landsat 8 OLI images were obtained at a Level-1T processing level, which includes standard radiometric, geometric and terrain correction using Ground Control Points and the Digital Elevation Model. The results of this step were visually inspected for accuracy with regard to the geometric overlay of the images and the LPIS database. No additional image to image registration was needed. The raw Digital Number data was converted to surface reflectance (Song et al., 2001) using FLAASH (Fast Line-of-sight Atmospheric Analysis of Hypercubes) in ENVI software (version 5.4), and any areas obscured by clouds were manually removed from the image.

From the LPIS database, both plots with grassland to cropland change and those on which the grassland remained were extracted. Plots detected as croplands in both time points (information acquired from LPIS also) were removed from the calculation. In the area of interest, 570 changed LPIS plots and 33,196 no-change LPIS plots were identified. To minimise the mixed pixel effect, only plots larger than 1 hectare with a non-elongated shape were selected. A non-elongated shape was defined as the proportion between the shape area (ha) and the shape length (m), which had to be greater than 0.045 . This threshold value was expertly set based on the visual inspection and knowledge of the LPIS database. On the acquired sample, a visual check that focused on the 
175 homogeneity of the selected plots was carried out based on the freely available orthophotos of the

176 Czech Republic. See Figure 3 for data processing workflow.

177 (Figure 3)

\section{2.4. Selection and calculation of the variables}

179 For each scene, 59 LULC change detection variables were calculated. Specifically, the calculated 180 variables included 36 vegetation indices, 10 textural characteristics, 7 components of Principal 181 Component Analysis, and 6 Tasselled Cap components (Table 1). The numbers of variables 182 represent, in our opinion, potentially used spectral and spatial indicators for change detection in 183 the ENVI software by a common user. The calculation of the variables was performed by 184 algorithms implemented in ENVI. Spectral-based variables were calculated from pre-processed spectral bands, while textural variables were calculated from the panchromatic band (see ENVI

186 help in Table 1). For each variable, the mean value for every plot of the LPIS-acquired database 187 was obtained using the ArcGIS (version 10.4) Zonal Statistics tool for both 2013 and 2016.

\section{8 (Table 1)}

\subsection{Statistical assessment}

190

To determine the optimal set of variables for grassland to cropland change detection, we first excluded the highly correlated ones $(r>0.9)$ from the full correlation matrix (see Supplement A). Where correlations were detected, only the variable most frequently used in the available literature was included into the subsequent analysis. From the original set of 59 variables, 41 were eliminated in preselection due to high correlation and the uncorrelated variables are presented in Table 2. 
197 lowest AIC (Akaike Information Criterion) (deLeeuw, 1992) using Generalised Linear Models

198 (GLM) with a defined binominal distribution of errors (more about GLM can be found, e.g., in

199 Dobson \& Barnett (2008)). Models, from one to seven members, were found by permutation of all

200 the combinations of variables with the 'glmulti' package in R (version 3.3.2). Models with a higher

201 number of variables than seven were best found by AIC in a Stepwise Algorithm in R because of

202 the time-consuming nature of the previous method. The calculated AIC values for the models

203 based on two - fourteen variables were very similar (only one-variable model using AIC values

204 was significantly different), so only the models, where the AIC values are at least slightly changed

205 (one, three, five, seven, fourteen), were chosen for the accuracy assessment.

206 2.6. Classification and Accuracy assessment

207 A practical accuracy assessment of the created models and the Landsat 8 images only (Table 3)

208 was undertaken using the object-based multi-temporal change detection. The variables of the

209 models from both years were merged, based on statistic calculation, into a single image (Layer

210 stacking tool). The training data for classification was selected from all of the 33,766 plots from

211 pre-prepared LPIS database (Section 2.3). Based on stratified random sample design, 300 plots

212 with change and 1200 without change were chosen (Congalton \& Green, 2009). Borders of

213 selected plots from LPIS database were used as the segments of the object-based classification.

214 Using slides consisting of variables and training data, change maps were created in ENVI software.

215 Due to non-normal distribution of the input data, the non-parametric Support Vector Machine

216 (SVM) classifier (Lu \& Weng, 2007) was used for classification. The settings of the SVM

217 algorithm was set as the default. The Kernel type: Radial Basic Function; Gamma in Kernel

218 Function: the inverse of the number of bands in the input image; The Penalty Parameter: 100; The

219 Pyramid Levels: 0; and the Classification Probability Threshold: 0. The same methodology was 
220

221

222

223

224

225

226

227

228

229

230

231

232

233

234

235

236

237

used for the change detection based only on the Landsat 8 images (the amount of training and validation samples, classification algorithm, etc.).

Finally, the accuracy of the change maps was calculated by comparison with stratified random validation (testing) samples extracted from the pre-prepared LPIS database (excluding the training data) using an confusion matrix. The sampling design was inspired by Zhen et al. (2013) and Olofsson et al. (2014). The assessment was based on evaluating the number of correctly classified 200 change and 800 no-change plots into change maps with validation plots from the LPIS database. A 95\% confidence interval was calculated from the overall accuracy of the models. The models accuracy has been tested with a homogeneity test of binominal distribution. The models have been tested against each other using Holm's p-value adjustment for multiple comparisons.

\section{Results}

\subsection{Models for change detection}

The lowest AIC was obtained from the model with fourteen variables (3950.90), the highest from the model using a single variable (5633.39). The single most significant variable was the NDVI (Normalised Difference Vegetation Index), which was represented in all the models. In the models with a lower number of variables, variables based on spectral information were predominantly used. The separability of the model with one variable (NDVI) is demonstrated by Figure 4 . With additional variables, textural variables began to play a greater role, see Table 3 . The summary of calculated models can be found in Supplement B.

(Table 3) (Figure 4)

\subsection{Change maps evaluation}

The overall accuracy of the change maps generally increases with the increasing number of 
243 variables in the models. The best change map was created from the highest number of variables

244 (89.80\% accuracy, Kappa 0.63), however classification based on a single variable provided only

245 slightly inferior results $(88.10 \%$ accuracy, Kappa 0.55$)$ as illustrated in Table 4 . These findings

246 were statistically confirmed by the homogeneity test for binominal distribution. So, we cannot

247 conclude (on a 95\% confidence level), that one of the models is more accurate, see Figure 5.

248 (Figure 5)

249 Looking more closely, the improvement in accuracy with an increasing number of variables

250 is associated only with the increasing Producer's Accuracy (PA) of the change class (one-variable 251 model $46.00 \%$ and fourteen-variable model $55.50 \%$ ). As shown in Table 4, there is an 252 improvement in the change class PA quality of the model between the models using one and three 253 variables. The rest of the confusion matrix parameters (User's Accuracy, Commission and 254 Omission) were very similar in all the cases. Contrary, the no-change detection did not show any 255 notable improvement with an increasing number of variables (PA 98.25 - 99.00\%). All change

256 maps, however, underestimated the number of change plots and overestimated the number of 257 grassland to cropland no-change plots (Figure 6). The results indicate that classification of the 258 change and no-change plots has achieved sufficient accuracy. If we compare the accuracy of the 259 change maps based on a statistically selected set of variables with change maps created from the 260 Landsat images (OA 90.40\%, Kappa 0.66), there is not any significant difference. The detailed 261 confusion matrices are available in Supplement C.

262 (Table 4) (Figure 6) 


\section{4. Discussion}

264 In accordance with the results, it is possible to use statistically selected variables for detection of

\section{5} grassland to cropland land cover changes. At first sight, it could be apparent that it is sufficient to only use the NDVI vegetation index for this type of analysis. However, based on the visual inspection of the misclassification in all the change maps and the confusion matrix (Supplement C), it is clear that the largest change detection inaccuracy is in a case when differentiating grassland and cropland plots with green plants. The largest number of these plots were poorly classified in the case of using only a one-variable model based on NDVI (the lowest Producer's Accuracy).

271 This result is not surprising because the surface reflectance of both categories is, in the spectral range of the Landsat 8 bands, almost identical and the NDVI index even uses two spectral bands (Red and Near Infrared). Only the NDVI variable can be used in the situation, when almost all plots are in the same phenological phase. However, this is not the case of our study and it is not common in the most of analyses, where some parts of the area (mountains vs. lowlands) are in different phenological phases. Therefore, the addition of some variables based on another spectral band is needed.

In our study, almost all vegetation indices were significantly correlated. The NDVI variable was chosen as the most appropriate because of its frequency of use in research. The statistical evaluation, however, indicates that very similar results would be achieved with any of the other vegetation indices closely correlated with the NDVI one, see the correlation matrices in Supplement A.

A good compromise among improving the accuracy of detection, the demands for computational time and complications of the interpretation of the obtained results, seems to be supplied by NDVI with the Wetness and Fifth components of Tasselled Cap (three-variable model 
287 cropland plots with the green plants. The advantage of the three-variable model is also the 288 relatively small number of variables, allowing the utilisation of methods based on the 289 determination of an optimal change detection threshold (Chen \& Rao, 2008; Otukei \& Blaschke, 290 2010). These findings related to crop phenology, besides other conclusions, point an importance 291 of appropriate time acquisition of satellite images. It also confirms the hypothesis about an 292 importance of this aspect for the grassland to cropland change detection.

The suitability of NDVI for the classification and change detection has been demonstrated

294 in several studies (Lunetta et al., 2006; Wardlow, Egbert \& Kastens, 2007; Pu et al., 2008; Bhandari, Kumar \& Singh, 2012; Esch et al., 2014; Aleksandrowicz et al., 2014; Gandhi et al., 296 2015; Nagendra et al., 2015) as well as in those studies successfully combining NDVI with

297

298

Tasselled Cap (e.g., Chen \& Rao, 2008).

Introducing too many variables into a model does not necessarily lead to achieving better results (Lu \& Weng, 2007), which underlines the importance of selecting the most appropriate variables for change detection. In this case, the best accuracy was achieved by using directly bands of Landsat image instead of calculated models due to almost all variables (outside the spatial variables) were based on similar spectral bands.

The study results could have been, theoretically, influenced by a number of uncertainties that we, however, strived to eliminate, e.g., through the pre-processing of the satellite images (atmospheric correction, registration of images and its visual verification). No object is shifted by more than $1 / 2$ a pixel between two frames (Dai, 1998). The selection of the Landsat 8 OLI pairs was predominantly limited by the launch of the satellite mission (2013) and by the cloud cover. Still, a suitable pair of pictures in a suitable phenological phase according to the recommendations (Coppin et al., 2004; Hájková et al., 2012; Esch et al., 2014; Tarantino et al., 2016) was found. 
310 The selection of the suitable acquisition period depends on the geographical conditions (especially

311 longitude, latitude or altitude) of the observed area. From this point of view, the presented methods

312 and results are relevant for similar environmental conditions in central Europe. Another

313 uncertainty is a possible error in the LPIS reference database as the land use data is entered directly

314 by the farmers themselves. Also, the information in the LPIS differs slightly from the date of

315 acquisition of the satellite imagery, as it refers to the end of the particular year. No better reference

316 database covering the entire territory of the Czech Republic on such a detailed scale is available

317 however. Moreover, using such a high number of individual plots combined with suitable

318 statistical methods ensured that even if the information was inaccurate by a small fraction, it should

319 not have any significant impact on the results of our study. The accuracy of the resulting change

320 maps could have been affected by selection of the change detection method also. An object-based

321 classification was used in the multi-temporal change detection as it is, according to literature, a

322 more suitable approach for high resolution data, when the pixels are significantly smaller than the

323 object. In this case, grouping pixels into segments is needed (Blaschke, 2010). The ratio of change

324 to no-change units in our study is approximately 1:50 and, therefore, the stratified random

325 sampling design with a proportion of 1:4 (change vs. no-change) for the training and validation

326 data was used.

LULC change detection most commonly employs Post-Classification Comparison (PCC)

328 (Otukei \& Blaschke, 2010), it is, therefore, rather a classification than a pure change detection task. For many applications, it is important to describe the trajectory of the change. On the other hand, the knowledge about the occurrence of (no-)change (so-called pre-classification, or bitemporal change detection (Coppin et al., 2004)) is sufficient for many other tasks. If this is the case, the choice of suitable variables is the key to acquiring quality results, and this is where the 
333 contribution of our study can be deemed significant. The methods used here can be applied to CDs

334 of other LULC categories as well. It is a well-known fact that finding suitable variables streamlines

335 analyses, while at the same time improves the results (Lu, Li \& Moran, 2014).

336 Our results indicate that we are nearing a maximum accuracy of the grassland to cropland

337 change detection achievable from a pair of high resolution multi-spectral images. Possible

338 improvements could be brought about by implementing new data into the models. Examples of

339 such supplementary data could include a time series of high resolution images, e.g. Landsat or

340 Sentinel-2 (Esch et al., 2014), very high resolution data (Tarantino et al., 2016), data with a

341 different resolution (Lu, Batistella \& Moran, 2008; Turker \& Ozdarici, 2011), data captured by

342 other RS methods (Smith \& Buckley, 2011), for example radar (Sentinel-1) and thermal data

343 (Landsat 8 TIRS) or the incorporation of an existing GIS database (Hussain et al., 2013).

344 Hussain et al. (2013) and Lu et al. (2003) both state that hybrid methods of change detection

345 combining multiple approaches can increase the accuracy of change detection.

346 The variables selected in this study can be used with sufficient precision as a source of data

347 for updating existing LULC databases or as a tool for setting agricultural subsidy policies and their

348 implementation. As the reference dataset used in the presented study was quite large, it is relatively

349 safe to assume the applicability of using the results for other studies addressing this change

350 detection problem in the whole of Central Europe. The results are relevant for areas with similar

351 geographical conditions, especially regarding the latitude. However, the selected statistical

352 methods and classification algorithms should be robust due to the used images (full scene of

353 Landsat 8) covered a large area with topographical variable conditions (lowlands, highlands,

354 mountains). 
355

356

357

358

359

360

361

362

363

364

365

366

367

368

369

370

371

372

373

374

375

376

377

\section{Conclusions}

This study provides an analysis of the utilisation of selected remote sensing variables (vegetation indices, textures, Principal Component Analysis, and Tasselled Cap analysis) for grassland to cropland change detection based on a pair of Landsat 8 OLI images and the Land Parcel Identification System (LPIS) vector database. The results confirm the principal hypotheses that (1) there are suitable variables usable for grassland to cropland change detection; (2) increasing the number of variables used in a model leads to increased accuracy of the change detection, but to achieve the highest accuracy, it is necessary to use original Landsat 8 bands; (3) spectral variables play a more important role than textural variables in the change detection; (4) the appropriate time of the acquisition satellite images is important for grassland to cropland change detection. In view of the accuracy of the created change maps, which was verified using the reference database, we consider a model utilising three variables (namely NDVI, Wetness and Fifth components) the most suitable. Incorporation of additional variables into the model does not significantly improve the accuracy of the change map. By analogy, the methods used in this study can be applied for the CD of other LULC categories than solely those based on grassland to cropland change. The models prepared in this way can serve as data sources for updating the current LULC databases or as a tool for creating agricultural subsidy policies. As the selection of variables was based on a large dataset of reference data on grassland to cropland change detection, the applicability for other studies can be safely assumed. Our conclusions are valid for analyses on a regional scale in Central Europe using high resolution data. To further improve the grassland to cropland change detection using RS, research combining our variables with spatial data acquired using other RS techniques is needed.

\section{Acknowledgments}


378

379

380

381

382

383

384

385

386

387

388

In advance, we acknowledge the anonymous referees for their constructive comments. Thanks to our colleagues from the Department of Applied Geoinformatics and Spatial Planning at the Czech University of Life Sciences Prague (CULS) for their helpful advice.

\section{References}

Aleksandrowicz S., Turlej K., Lewiński S., Bochenek Z. 2014. Change detection algorithm for the production of land cover change maps over the European union countries. Remote Sensing 6:5976-5994. DOI: 10.3390/rs6075976.

Atzberger C. 2013. Advances in remote sensing of agriculture: Context description, existing operational monitoring systems and major information needs. Remote Sensing 5:949-981. DOI: $10.3390 /$ rs5020949.

Bannari A., Morin D., Bonn F., Huete AR. 1995. A review of vegetation indices. Remote Sensing Reviews 13:95-120. DOI: 10.1080/02757259509532298.

Barry S., Elith J. 2006. Error and uncertainty in habitat models. Journal of Applied Ecology 43:413-423. DOI: 10.1111/j.1365-2664.2006.01136.x.

Berberoglu S., Akin A. 2009. Assessing different remote sensing techniques to detect land use/cover changes in the eastern Mediterranean. International Journal of Applied Earth Observation and Geoinformation 11:46-53. DOI: 10.1016/j.jag.2008.06.002.

Bergen KM., Brown DG., Rutherford JF., Gustafson EJ. 2005. Change detection with heterogeneous data using ecoregional stratification, statistical summaries and a land allocation algorithm. Remote Sensing of Environment 97:434-446. DOI: 10.1016/j.rse.2005.03.016.

Bhandari a. K., Kumar a., Singh GK. 2012. Feature Extraction using Normalized Difference Vegetation Index (NDVI): A Case Study of Jabalpur City. Procedia Technology 6:612-621. DOI: $10.1016 /$ j.protcy.2012.10.074.

Blaschke T. 2010. Object based image analysis for remote sensing. ISPRS Journal of Photogrammetry and Remote Sensing 65:2-16. DOI: 10.1016/j.isprsjprs.2009.06.004.

Cardinale BJ., Duffy JE., Gonzalez A., Hooper DU., Perrings C., Venail P., Narwani A., Mace GM., Tilman D., A.Wardle D., Kinzig AP., Daily GC., Loreau M., Grace JB., Larigauderie 
406

407

408

409

410

411

412

413

414

415

416

417

418

419

420

421

422

423

424

425

426

427

428

429

430

431

432

433

A., Srivastava DS., Naeem S. 2012. Biodiversity loss and its impact on humanity. Nature 489:326-326. DOI: 10.1038/nature11373.

Congalton RG., Green K. 2009. Assessing the Accuracy of Remotely Sensed Data.

Coppin P., Bauer M. 1996. Digital change detection in forest ecosystems with remote sensing imagery. Remote sensing reviews 13:207-234. DOI: 10.1080/02757259609532305.

Coppin P., Jonckheere I., Nackaerts K., Muys B., Lambin E. 2004. Digital change detection methods in ecosystem monitoring: a review. International Journal of Remote Sensing 25:1565-1596. DOI: 10.1080/0143116031000101675.

Dai X. 1998. The effects of image misregistration on the accuracy of remotely sensed change detection. IEEE Transactions on Geoscience and Remote Sensing 36:1566-1577. DOI: 10.1109/36.718860.

deLeeuw J. 1992. Introduction to Akaike (1973) Information Theory and an Extension of the Maximum Likelihood Principle. In: Kotz S, Johnson NL eds. Breakthroughs in Statistics: Foundations and Basic Theory. New York, NY: Springer New York, 599-609. DOI: 10.1007/978-1-4612-0919-5_37.

Dobson AJ., Barnett A. 2008. An Introduction to Generalized Linear Models. DOI: $10.1002 /$ pst.486.

Esch T., Metz A., Marconcini M., Keil M. 2014. Combined use of multi-seasonal high and medium resolution satellite imagery for parcel-related mapping of cropland and grassland. International Journal of Applied Earth Observation and Geoinformation 28:230-237. DOI: 10.1016/j.jag.2013.12.007.

European Union. 2016. Eurostat regional yearbook - 2016 edition. :274. DOI: 10.2785/29084.

Eurostat. 2017.Land cover statistics - Statistics Explained. Available at http://ec.europa.eu/eurostat/statisticsexplained/index.php/Land_cover_statistics\#Land_cover_in_the_EU (accessed August 8, 2017).

Exelis Visual Information Solutions. 2015. ENVI Help.

Gandhi GM., Parthiban S., Thummalu N., Christy A. 2015. Ndvi: Vegetation Change Detection 
434

435

436

437

438

439

440

441

442

443

444

445

446

447

448

449

450

451

452

453

454

455

456

457

458

459

460

461

Using Remote Sensing and Gis - A Case Study of Vellore District. In: Procedia Computer Science. Elsevier Masson SAS, 1199-1210. DOI: 10.1016/j.procs.2015.07.415.

Gupta SK., Shukla DP. 2016. Assessment of land use/land cover dynamics of Tso Moriri Lake, a Ramsar site in India. Environmental Monitoring and Assessment 188. DOI: 10.1007/s10661-016-5707-3.

Hájková L., Voženílek V., Tolasz R., Kohut M., Možný M., Nekovář J., Novák M., Richterová D., Stř̌ž M., Vávra A., Vondráková A. 2012. Atlas fenologických pomérů Česka. Olomouc: Univerzita Palackého v Olomouci.

Hussain M., Chen D., Cheng A., Wei H., Stanley D. 2013. Change detection from remotely sensed images: From pixel-based to object-based approaches. ISPRS Journal of Photogrammetry and Remote Sensing 80:91-106. DOI: 10.1016/j.isprsjprs.2013.03.006.

Chaudhuri G., Mishra NB. 2016. Spatio-temporal dynamics of land cover and land surface temperature in Ganges-Brahmaputra delta: A comparative analysis between India and Bangladesh. Applied Geography 68:68-83. DOI: 10.1016/j.apgeog.2016.01.002.

Chen G., Hay GJ., Carvalho LMT., Wulder MA. 2012. Object-based change detection. International Journal of Remote Sensing 33:4434-4457. DOI: 10.1080/01431161.2011.648285.

Chen S., Rao P. 2008. Land degradation monitoring using multi-temporal Landsat TM/ETM data in a transition zone between grassland and cropland of northeast China. International Journal of Remote Sensing 29:2055-2073. DOI: 10.1109/ICISE.2009.878.

Jensen JR. 1996. Introductory digital image processing: a remote sensing perspective. Second edition. Toronto: Prentice Hall. DOI: 10.2113/gseegeosci.13.1.89.

Kindu M., Schneider T., Teketay D., Knoke T. 2013. Land use/land cover change analysis using object-based classification approach in Munessa-Shashemene landscape of the ethiopian highlands. Remote Sensing 5:2411-2435. DOI: 10.3390/rs5052411.

Klouček T., Lagner O., Šímová P. 2015. How does data accuracy influence the reliability of digital viewshed models? A case study with wind turbines. Applied Geography 64:46-54. DOI: 10.1016/j.apgeog.2015.09.005. 
462 Klouček T. 2016. Detection of Land Cover Change Focusing on Agricultural Land. Charles 463 University in Prague.

464 Kupková L., Bičík I. 2016. Landscape transition after the collapse of communism in Czechia.

465

466

467

468

469

470

471

472

473

474

475

476

477

478

479

480

481

482

483

484

485

486

487

488

489

Journal of Maps 5647:1-6. DOI: 10.1080/17445647.2016.1195301.

Liu H., Zhou Q. 2004. Accuracy analysis of remote sensing change detection by rule-based rationality evaluation with post-classification comparison. International Journal of Remote Sensing 25:1037-1050. DOI: 10.1080/0143116031000150004.

Lu D., Batistella M., Moran E. 2008. Integration of Landsat TM and SPOT HRG Images for Vegetation Change Detection in the Brazilian Amazon. Photogrammetric Engineering \& Remote Sensing 74:421-430. DOI: 10.14358/PERS.74.4.421.

Lu D., Li G., Moran E. 2014. Current situation and needs of change detection techniques. International Journal of Image and Data Fusion 5:13-38. DOI: 10.1080/19479832.2013.868372.

Lu D., Mausel P., Brondízios E., Moran E. 2003. Change detection techniques. International Journal of Remote Sensing 25:2365-2407. DOI: 10.1080/0143116031000139863.

Lu D., Weng Q. 2007. A survey of image classification methods and techniques for improving classification performance. International Journal of Remote Sensing 28:823-870. DOI: 10.1080/01431160600746456.

Lunetta RS., Knight JF., Ediriwickrema J., Lyon JG., Worthy LD. 2006. Land-cover change detection using multi-temporal MODIS NDVI data. Remote Sensing of Environment 105:142-154. DOI: 10.1016/j.rse.2006.06.018.

Lyon JG., Yuan D., Lunetta RS., Elvidge CD. 1998. A change detection experiment using vegetation indices. Photogrammetric Engineering and Remote Sensing 64:143-150. DOI: citeulike-article-id:7262520.

Mas J-F. 1999. Monitoring land-cover changes: a comparison of change detection techniques. International Journal of Remote Sensing 20:139-152. DOI: 10.1080/014311699213659.

Moudrý V., Šímová P. 2012. Influence of positional accuracy, sample size and scale on modelling species distributions: a review. International Journal of Geographical 
490

491

492

493

494

495

496

497

498

499

500

501

502

503

504

505

506

507

508

509

510

511

512

513

514

515

516

517

518

Information Science 8816:1-13. DOI: 10.1080/13658816.2012.721553.

Müller H., Rufin P., Griffiths P., Barros Siqueira AJ., Hostert P. 2015. Mining dense Landsat time series for separating cropland and pasture in a heterogeneous Brazilian savanna landscape. Remote Sensing of Environment 156:490-499. DOI: 10.1016/j.rse.2014.10.014.

Nagendra H., Mairota P., Marangi C., Lucas R., Dimopoulos P., Honrado JP., Niphadkar M., Mücherg CA., Tomaselli V., Panitsa M., Tarantino C., Manakos I., Blonda P. 2015. Satellite Earth observation data to identify anthropogenic pressures inselected protected areas. International Journal of Applied Earth Observation and Geoinformation 37:124-132. DOI: 10.1016/j.jag.2014.10.010.

Olofsson P., Foody GM., Herold M., Stehman S V., Woodcock CE., Wulder MA. 2014. Good practices for estimating area and assessing accuracy of land change. Remote Sensing of Environment 148:42-57. DOI: 10.1016/j.rse.2014.02.015.

Otukei JR., Blaschke T. 2010. Land cover change assessment using decision trees, support vector machines and maximum likelihood classification algorithms. International Journal of Applied Earth Observation and Geoinformation 12. DOI: 10.1016/j.jag.2009.11.002.

Pazúr R., Lieskovský J., Feranec J., Ot'ahel' J. 2014. Spatial determinants of abandonment of large-scale arable lands and managed grasslands in Slovakia during the periods of postsocialist transition and European Union accession. Applied Geography 54:118-128. DOI: 10.1016/j.apgeog.2014.07.014.

Pu R., Gong P., Tian Y., Miao X., Carruthers RI., Anderson GL. 2008. Using classification and NDVI differencing methods for monitoring sparse vegetation coverage: a case study of saltcedar in Nevada, USA. International Journal of Remote Sensing 29:3987-4011. DOI: 10.1080/01431160801908095.

Roy M., Ghosh S., Ghosh A. 2014. A novel approach for change detection of remotely sensed images using semi-supervised multiple classifier system. Information Sciences 269:35-47. DOI: 10.1016/j.ins.2014.01.037.

Roy DP., Wulder MA., Loveland TR., C.E. W., Allen RG., Anderson MC., Helder D., Irons JR., Johnson DM., Kennedy R., Scambos TA., Schaaf CB., Schott JR., Sheng Y., Vermote EF., Belward AS., Bindschadler R., Cohen WB., Gao F., Hipple JD., Hostert P., Huntington J., 
519

520

521

522

523

524

525

526

527

528

529

530

531

532

533

534

535

536

537

538

539

540

541

542

543

544

545

546

547

Justice CO., Kilic A., Kovalskyy V., Lee ZP., Lymburner L., Masek JG., McCorkel J., Shuai Y., Trezza R., Vogelmann J., Wynne RH., Zhu Z. 2014. Landsat-8: Science and product vision for terrestrial global change research. Remote Sensing of Environment 145:154-172. DOI: 10.1016/j.rse.2014.02.001.

Singh A. 1989. Digital change detection techniques using remotely sensed data. Int $J$ Remote Sens 10:989-1003. DOI: 10.1080/01431168908903939.

Sklenicka P., Molnarova KJ., Salek M., Simova P., Vlasak J., Sekac P., Janovska V. 2015. Owner or tenant: Who adopts better soil conservation practices? Land Use Policy 47:253261.

Sklenicka P., Šímová P., Hrdinová K., Salek M. 2014. Changing rural landscapes along the border of Austria and the Czech Republic between 1952 and 2009: Roles of political, socioeconomic and environmental factors. Applied Geography 47:89-98. DOI: 10.1016/j.apgeog.2013.12.006.

Smith AM., Buckley JR. 2011. Investigating RADARSAT-2 as a tool for monitoring grassland in western Canada. Canadian Journal of Remote Sensing 37:93-102. DOI: 10.5589/m11027.

Sohn G., Dowman I. 2007. Data fusion of high-resolution satellite imagery and LiDAR data for automatic building extraction. ISPRS Journal of Photogrammetry and Remote Sensing 62:43-63. DOI: 10.1016/j.isprsjprs.2007.01.001.

Song C., Woodcock CE., Seto KC., Lenney MP., Macomber SA. 2001. Classification and change detection using Landsat TM data: When and how to correct atmospheric effects?

Remote Sensing of Environment 75:230-244. DOI: 10.1016/S0034-4257(00)00169-3.

Tarantino C., Adamo M., Lucas R., Blonda P. 2016. Detection of changes in semi-natural grasslands by cross correlation analysis with WorldView-2 images and new Landsat 8 data. Remote Sensing of Environment 175:65-72. DOI: 10.1016/j.rse.2015.12.031.

Tasser E., Leitinger G., Tappeiner U. 2017. Climate change versus land-use change - What affects the mountain landscapes more? Land Use Policy 60:60-72. DOI:

10.1016/j.landusepol.2016.10.019.

Tewkesbury AP., Comber AJ., Tate NJ., Lamb A., Fisher PF. 2015. A critical synthesis of 
remotely sensed optical image change detection techniques. Remote Sensing of Environment 160:1-14. DOI: 10.1016/j.rse.2015.01.006.

550

551

552

553

554

555

556

557

558

559

560

561

562

563

564

565

566

567

568

569

570

571

572

573

574

575

576

The Ministry of Agriculture of the Czech Republic. 2016.LPIS - modul iLPIS. Available at $z$ : http://eagri.cz/public/web/file/2127/LPIS_modul_iLPIS_prirucka_20140831.pdf(accessed March 21, 2017).

Turker M., Ozdarici A. 2011. Field-based crop classification using SPOT4, SPOT5, IKONOS and QuickBird imagery for agricultural areas: a comparison study. International Journal of Remote Sensing 32:9735-9768. DOI: 10.1080/01431161.2011.576710.

Vorovencii I. 2014. Assessment of some remote sensing techniques used to detect land use/land cover changes in South-East Transilvania, Romania. Environmental Monitoring and Assessment 186:2685-2699. DOI: 10.1007/s10661-013-3571-y.

Wardlow BD., Egbert SL., Kastens JH. 2007. Analysis of time-series MODIS 250 m vegetation index data for crop classification in the U.S. Central Great Plains. Remote Sensing of Environment 108:290-310. DOI: 10.1016/j.rse.2006.11.021.

Weeks ES., Ausseil AGE., Shepherd JD., Dymond JR. 2013. Remote sensing methods to detect land-use/cover changes in New Zealand's "indigenous" grasslands. New Zealand Geographer 69:1-13. DOI: Doi 10.1111/Nzg.12000.

Wondrade N., Dick ØB., Tveite H. 2014. GIS based mapping of land cover changes utilizing multi-temporal remotely sensed image data in Lake Hawassa Watershed, Ethiopia. Environmental Monitoring and Assessment 186:1765-1780. DOI: 10.1007/s10661-0133491-x.

Woodcock CE., Macomber SA., Pax-Lenney M., Cohen WB. 2001. Monitoring large areas for forest change using Landsat: Generalization across space, time and Landsat sensors. Remote Sensing of Environment 78:194-203. DOI: 10.1016/S0034-4257(01)00259-0.

Wulder MA., White JC., Goward SN., Masek JG., Irons JR., Herold M., Cohen WB., Loveland TR., Woodcock CE. 2008. Landsat continuity: Issues and opportunities for land cover monitoring. Remote Sensing of Environment 112:955-969. DOI: 10.1016/j.rse.2007.07.004.

Xian G., Homer C., Fry J. 2009. Updating the 2001 National Land Cover Database land cover classification to 2006 by using Landsat imagery change detection methods. Remote Sensing 
577 of Environment 113:1133-1147. DOI: 10.1016/j.rse.2009.02.004.

578 Yin H., Pflugmacher D., Kennedy RE., Sulla-Menashe D., Hostert P. 2014. Mapping annual land 579 use and land cover changes using MODIS time series. IEEE Journal of Selected Topics in $580 \quad$ Applied Earth Observations and Remote Sensing 7:3421-3427. DOI:

$581 \quad$ 10.1109/JSTARS.2014.2348411.

582 Zhen Z., Quackenbush LJ., Stehman S V., Zhang L. 2013. Impact of training and validation 583 sample selection on classification accuracy and accuracy assessment when using reference 584 polygons in object-based classification. International Journal of Remote Sensing 34:6914585 6930. DOI: $10.1080 / 01431161.2013 .810822$. 
Figure 1

The study area is (located in the Czech Republic, specifically) comprising a part of Landsat 8 scene Path 192 Row 25.

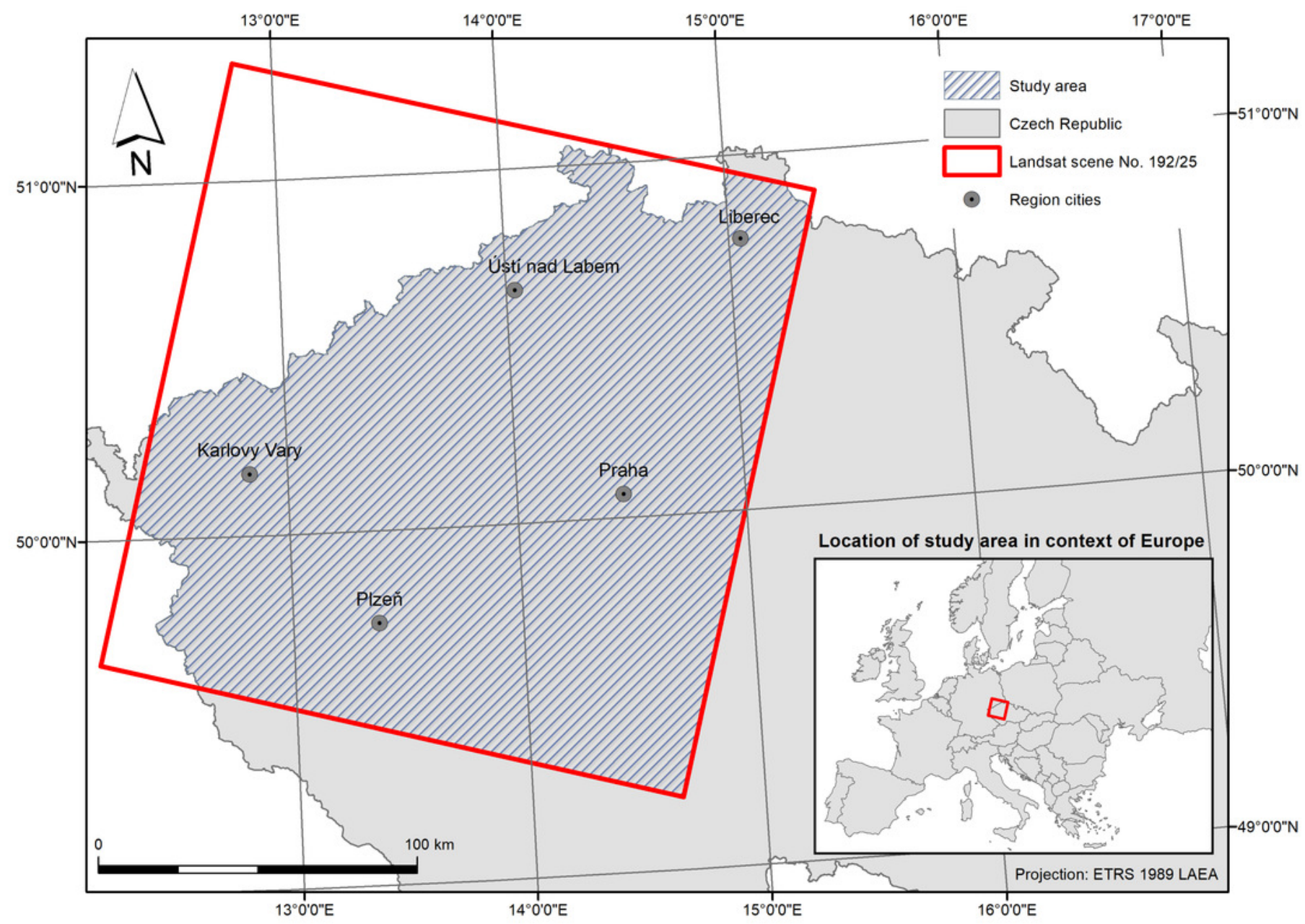


Figure 2

An example of used datasets. Landsat 8 images, NDVI vegetation index, and (no)change grassland to cropland plots (LPIS database) from 2013 and 2016.

(A) Landsat 8 image from 2013. (B) Landsat 8 image from 2016. (C) NDVI RGB composite (R $=$ NDVI 2013, $G=$ NDVI 2016, $B=$ NDVI 2013).

(D) (No-)change grassland to cropland plots from LPIS database.
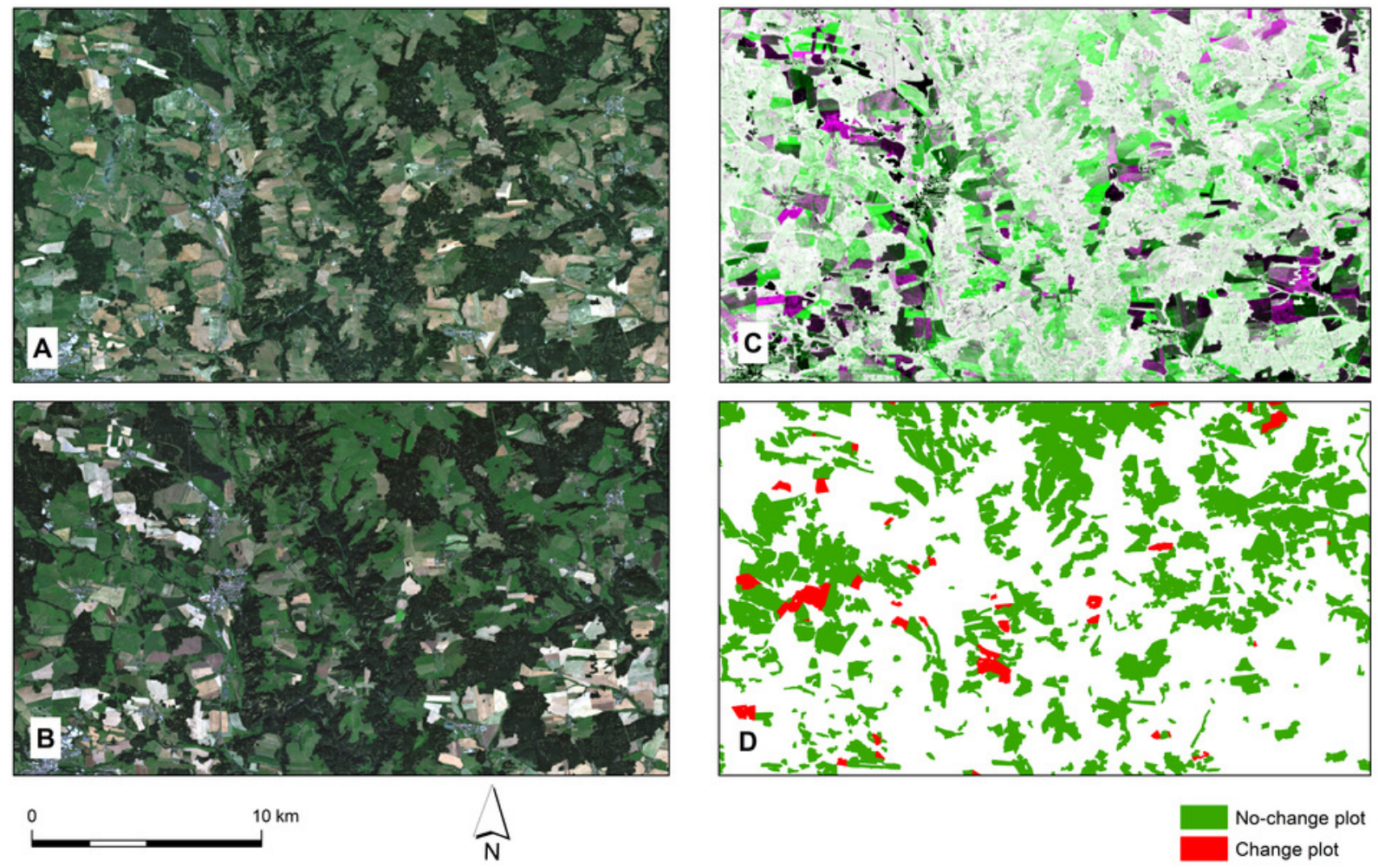
Figure 3

A scheme of the study methods describing data processing workflow.

For validation of models was used multi-temporal change detection based on object-based classification using Support Vector Machine algorithm.

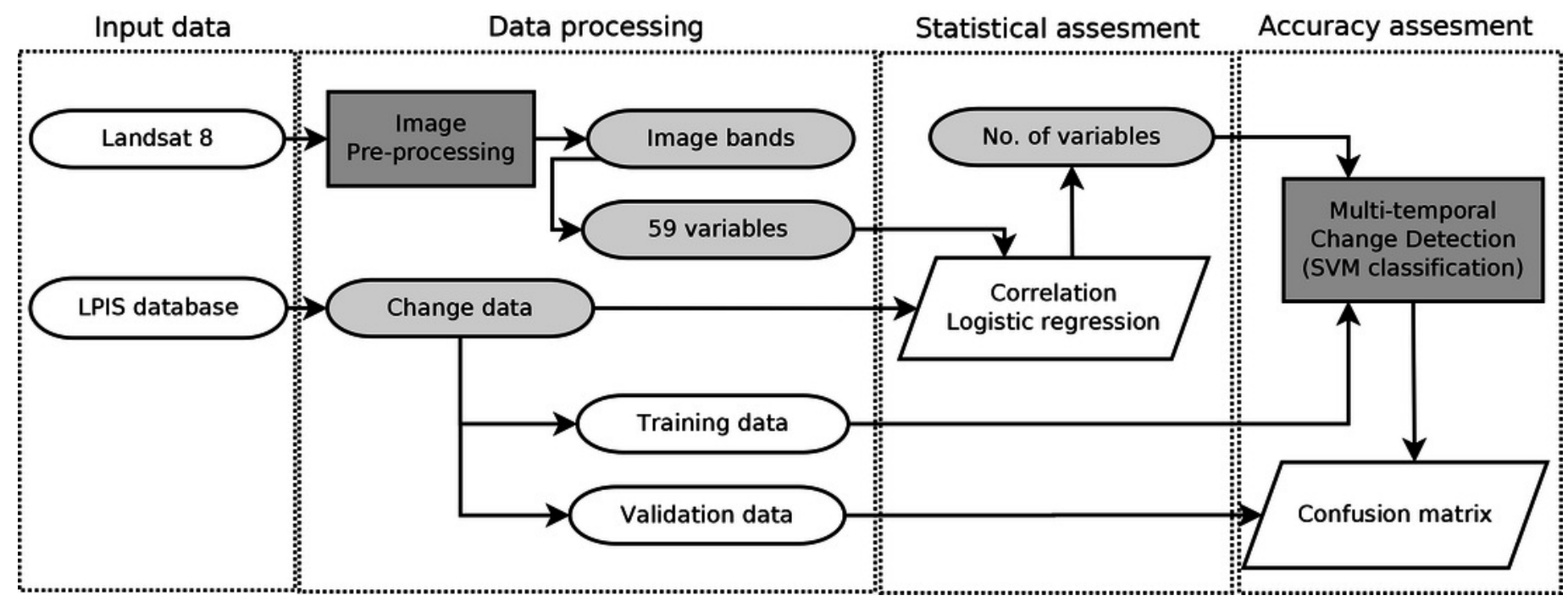


Figure 4

2D scatter plot created from NDVI average values of change and no-change plots.

Points represent training data (300 change, 1200 no-change plots). X-axis belongs to NDVI 2016 and Y-axis belongs to NDVI 2013 (one-variable model).

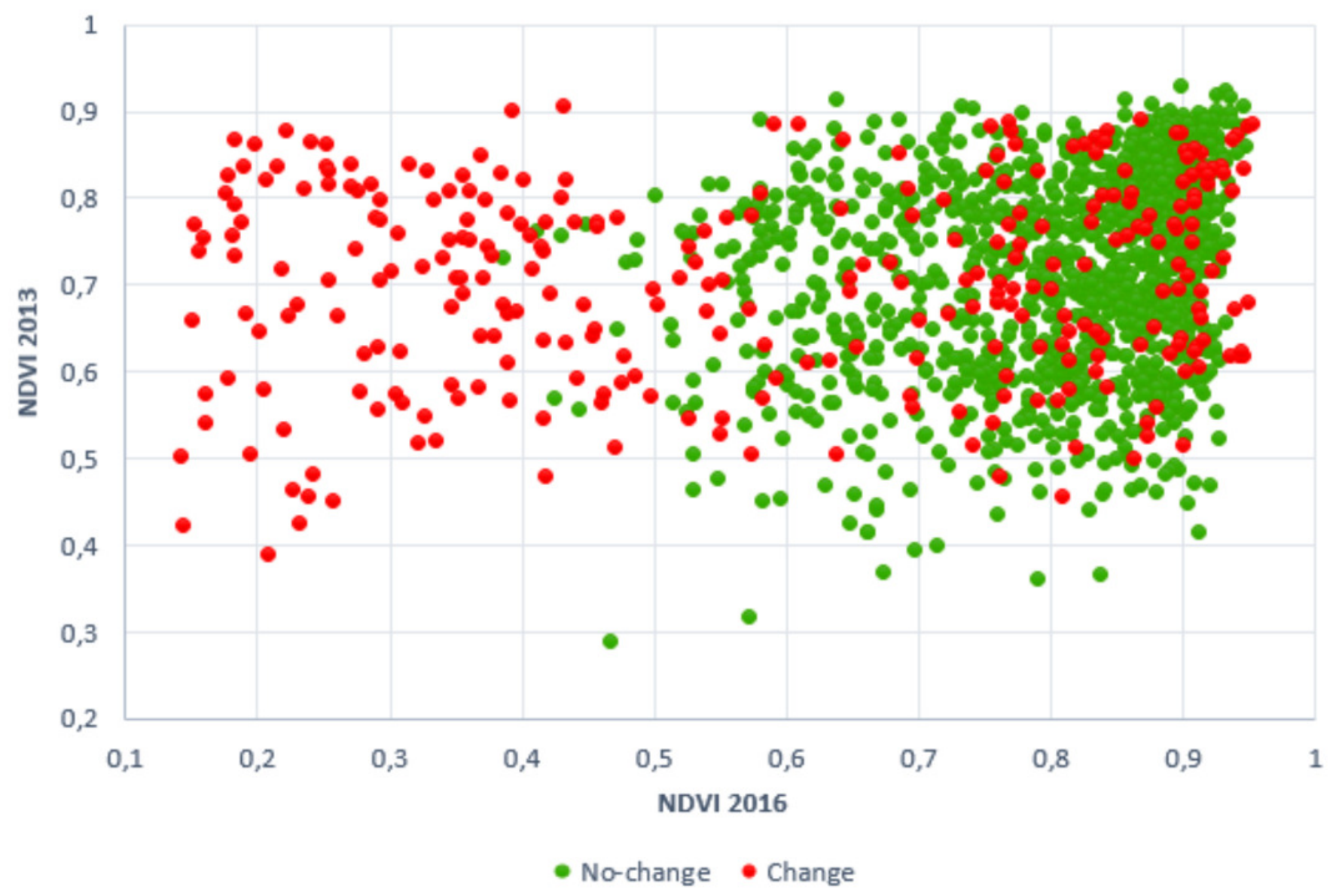


Figure 5

Overall accuracy (\%) of calculated models with 95\% confidence intervals.

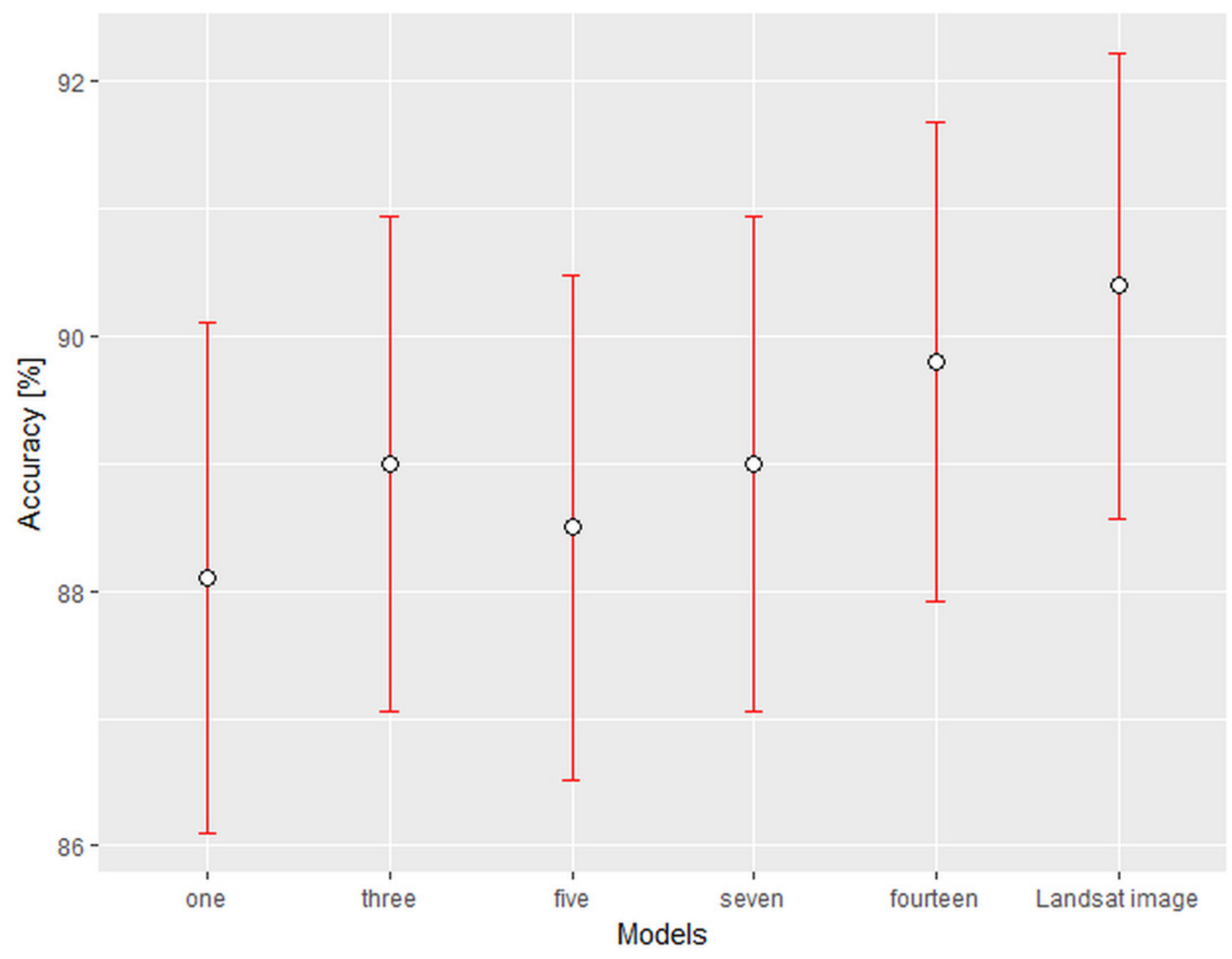


Figure 6

Comparison of created change maps with Landsat 8 images and LPIS database.

(A) One-variable model. (B) Three-variable model. (C) Fourteen-variable model. (D) Landsat 8 images only model. (E) Landsat 8 image from 2013. (F) Landsat 8 image from 2018 with (no)change plots from LPIS database.
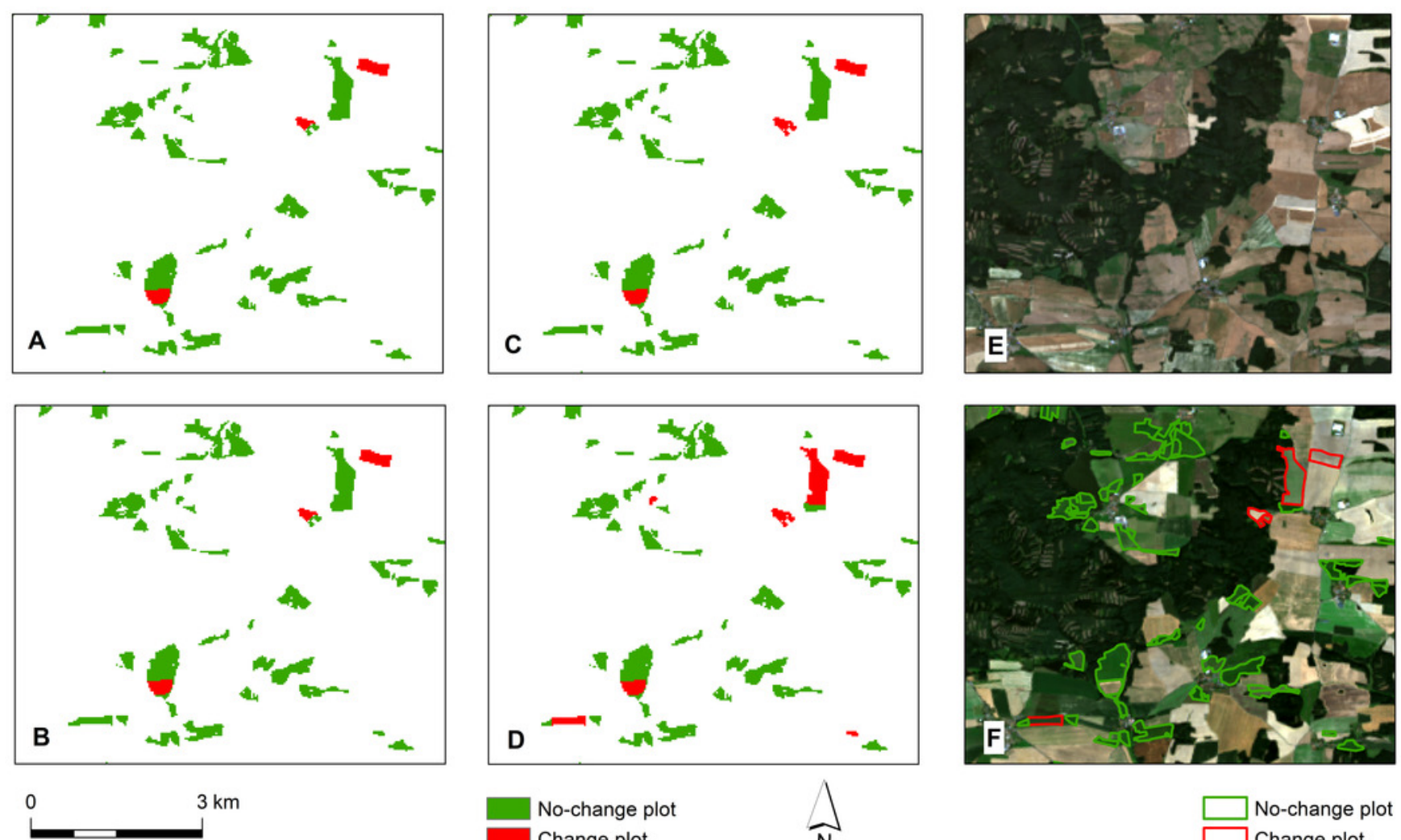

No-change plot

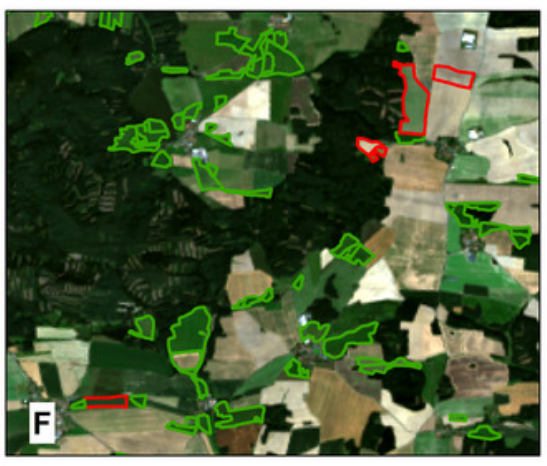




\section{Table $\mathbf{1}$ (on next page)}

59 change detection variables used in the study for detection of (no-)change from grassland to cropland.

Specifically, 36 vegetation indices, 10 texture characteristics, 7 components of Principal Component Analysis and 6 components of Tasseled Cap were used. Numbers represent almost all available variables in ENVI software. For details see external links. 


\begin{tabular}{ll}
\hline Group & Change detection variables \\
\hline & Atmospherically Resistant Vegetation Index, Burn Area Index, Clay Minerals, Difference \\
& Vegetation Index, Enhanced Vegetation Index, Ferrous Minerals, Global Environmental Monitoring \\
& Index, Green Atmospherically Resistant Index, Green Difference Vegetation Index, Green \\
& Normalized Difference Vegetation Index, Green Ratio Vegetation Index, Green Vegetation Index, \\
& Infrared Percentage Vegetation Index, Iron Oxide, Leaf Area Index, Modified Non Linear Index, \\
Vegetation & Modified Normalized Difference Water Index, Modified Simple Ratio, Modified Triangular \\
Indices & Vegetation Index, Modified Triangular Vegetation Index, Improved Non-Linear Index, Normalized \\
& Burn Ratio, Normalized Difference Built Up Index, Normalized Difference Snow Index, \\
Normalized Difference Vegetation Index, Optimized Soil Adjusted Vegetation Index, Red Green \\
Tasseled Cap & Ratio Index, Renormalized Difference Vegetation Index, Simple Ratio, Soil Adjusted Vegetation \\
Principal & Index, Structure Insensitive Pigment Index, Sum Green Index, Transformed Difference Vegetation \\
Component & Index, Visible Atmospherically Resistant Index, WorldView Improved Vegetative Index, \\
& WorldView Water Index \\
& PCA 1, PCA 2, PCA 3, PCA 4, PCA 5, PCA 6, PCA 7 \\
& Moment, Variance
\end{tabular}

1 For more information about the variables visit

2 http://www.harrisgeospatial.com/docs/alphabeticallistspectralindices.html or

3 http://www.harrisgeospatial.com/docs/backgroundtexturemetrics.html. 


\section{Table 2(on next page)}

Non-correlated variables used for detecting grassland to cropland (no-)changes. 


\begin{tabular}{ll}
\hline Group & Not correlated variables \\
\hline Vegetation Indices & $\begin{array}{l}\text { Normalized Difference Vegetation Index, Simple Ratio, Sum } \\
\text { Green Index }\end{array}$ \\
$\begin{array}{l}\text { Contrast, Data Range, Entropy, Homogenity, Mean, Second } \\
\text { Moment, Skewness }\end{array}$ \\
$\begin{array}{l}\text { Principal Component } \\
\text { Analysis }\end{array}$ & PCA 1, PCA 2, PCA 3, PCA 4, PCA 7 \\
Tasseled Cap & Brightness, Wetness, Fifth \\
\hline
\end{tabular}

1 


\section{Table 3(on next page)}

Summary of the validated models for the grassland to cropland change detection based on different set of variables.

The value of AIC specifies the information potential of models. 


\begin{tabular}{llc}
\hline No. of variables & Change detection model & AIC $^{\mathbf{1}}$ \\
\hline One & Normalized Difference Vegetation Index & $\mathbf{5 6 3 3 . 3 9}$ \\
Three & Normalized Difference Vegetation Index, Wetness, Fifth & $\mathbf{4 5 9 2 . 4 1}$ \\
Five & $\begin{array}{l}\text { Normalized Difference Vegetation Index, Wetness, Fifth, Brightness, } \\
\text { Sum Green Index }\end{array}$ & $\mathbf{4 2 6 3 . 7 4}$ \\
Seven & $\begin{array}{l}\text { Normalized Difference Vegetation Index, Wetness, Fifth, Brightness, } \\
\text { Sum Green Index, Second Moment, PCA 2 }\end{array}$ & $\mathbf{4 0 6 0 . 3 5}$ \\
& $\begin{array}{l}\text { Normalized Difference Vegetation Index, Wetness, Fifth, Brightness, } \\
\text { Fourteen }\end{array}$ & $\begin{array}{l}\text { Sum Green Index, Second Moment, PCA 2, PCA 1, PCA 3, PCA 4, } \\
\text { PCA 7, Data Range, Contrast, Skewness }\end{array}$ \\
\hline
\end{tabular}




\section{Table 4 (on next page)}

The accuracy of models (\%) calculated based on different sets of variables by nonparametric classifiers Support Vector Machine (SVM).

$\mathrm{PA}=$ Producer's Accuracy (\%), UA = User's Accuracy (\%), OA = Overall Accuracy $(\%), 95 \% \mathrm{Cl}$ $=95 \%$ Confidence Interval $(\%)$ and Kappa coefficient. 


\begin{tabular}{ccccccc}
\hline $\begin{array}{c}\text { No. of } \\
\text { variables/model }\end{array}$ & Change PA & No-change PA & Change UA & No-change UA & OA & 95\% CI \\
\hline One & 46.00 & 98.63 & 89.32 & 87.96 & $\mathbf{8 8 . 1 0}$ & $86.09-90.11$ \\
Three & 49.50 & 98.88 & 91.67 & 88.68 & $\mathbf{8 9 . 0 0}$ & $87.07-90.94$ \\
Five & 46.50 & 99.00 & 92.08 & 88.10 & $\mathbf{8 8 . 5 0}$ & $86.52-90.48$ \\
Seven & 52.00 & 98.25 & 88.14 & 89.12 & $\mathbf{8 9 . 0 0}$ & $87.06-90.94$ \\
Fourteen & 55.50 & 98.38 & 89.52 & 89.84 & $\mathbf{8 9 . 8 0}$ & $87.93-91.68$ \\
Landsat image & 59.00 & 98.25 & 89.39 & 90.55 & $\mathbf{9 0 . 4 0}$ & $88.57-92.23$ \\
\hline
\end{tabular}

1 